This item was submitted to Loughborough's Research Repository by the author.

Items in Figshare are protected by copyright, with all rights reserved, unless otherwise indicated.

\title{
Evidence translation: an exploration of policy makers' use of evidence
}

PLEASE CITE THE PUBLISHED VERSION

http://dx.doi.org/10.1332/147084414X13988707323088

PUBLISHER

(C) Policy Press

VERSION

AM (Accepted Manuscript)

PUBLISHER STATEMENT

This work is made available according to the conditions of the Creative Commons Attribution-NonCommercialNoDerivatives 4.0 International (CC BY-NC-ND 4.0) licence. Full details of this licence are available at: https://creativecommons.org/licenses/by-nc-nd/4.0/

\section{LICENCE}

CC BY-NC-ND 4.0

\section{REPOSITORY RECORD}

Ingold, Jo, and Mark Monaghan. 2016. "Evidence Translation: An Exploration of Policy Makers' Use of Evidence". Loughborough University. https://hdl.handle.net/2134/21322. 


\section{Evidence translation: an exploration of policymakers' use of evidence}

\section{Introduction}

Centuries ago, the philosopher Thomas Hobbes recognised that some relationship between learning and policy formulation was a desirable enterprise and that sovereign powers could and should be influenced by scholarship (Parsons, 1995). Such ideas enjoy continued salience and are widely accepted by the scientific and policy communities at the level of rhetoric, if not reality. In recent years, many Western governments and agencies have committed themselves to the process of designing, developing, implementing and evaluating policies with a strong research base. In essence, they have signed up to a programme of evidencebased policymaking (EBPM) within an emerging 'knowledge economy', in which competitive advantage is maximised through the production, accumulation and transfer (or translation) of knowledge (see for example Lapaige, 2010).

Concomitant to debates over the desirability, or otherwise, of evidence-based policy have been other dilemmas, such as how to utilise evidence, ideas or knowledge, including those developed in other jurisdictions: a process known as 'policy transfer' (Dolowitz, 1998). More recently, 'policy as translation' (Lendvai and Stubbs, 2007; Freeman, 2009) has been employed to critique the rationalist and linear assumptions of policy transfer and has drawn attention to the complexity underlying this process (Stone, 2012). There has been a significant degree of academic interest in this journal (and elsewhere) in 'policy learning' more broadly (see for example Dolowitz et al, 2012; Ettelt et al, 2012; Hulme and Hulme, 2012). Some authors have focused on the barriers and facilitators to realising the ideal of basing policy on the best available evidence. These include the blurring of boundaries between the evidence and policy communities in a 'post-ideological' policy context (Newman, 2011); the role of special advisors in shaping policy agendas and the evidence-base (Gains and Stoker, 2011); and how a preference for 'home grown' solutions over overseas imports is contingent on the level of government decision-making (Nutley et al, 2012).

Hulme and Hulme (2012) have rightly suggested that the EBPM and policy transfer/translation literatures are concerned with similar themes, but have largely emerged separately. Legrand (2012) is one of the few authors who has attempted to fuse the literatures, arguing that New Labour's preoccupation with 'what works' played a crucial role in the adoption of US evidence-based welfare to work policies. This paper aims to further the debate. Firstly, we examine the complementarities and disjuncture in the EBPM and policy transfer literatures, employing 'policy as translation' to illuminate the debate regarding whether and how domestic and international evidence is used in policy. Whereas evidence scholars tend to ignore translation and translation scholars ignore the evidence-based literature, we combine both. Secondly we augment our discussion by gaining rare 'insider' accounts from government officials in the Department for Work and Pensions concerning how evidence is used policymaking. Finally, we present a conceptual model of 'Evidence Translation' to attempt to more accurately explain this relationship. The model takes into account the views of officials and is characterised by five key dimensions which impact upon 'evidence translation': the perceived policy problem, agenda-setting, filtration processes, policy apparatus and the role of translators. We argue that agency is crucial at every stage of 
this recursive process and suggest that methodology is an overlooked but important selection mechanism for evidence translation.

\section{The fluctuating fortunes of EBPM}

Policymaking takes place in the context of uncertain conditions and increasingly complex policy problems (Downe et al, 2012; Sanderson, 2002, 2009; Pawson, 2013). At the same time there is a stated desire to formulate policies based on the best available evidence. Under New Labour in the UK this was encapsulated by the term 'evidence-based policy making' and the associated search for 'what works'. The latter traditionally relied on the findings of programme evaluations, sometimes including Randomised Controlled Trials or 'systematic reviews' of the evidence. Almost from the outset this view of policymaking attracted criticism as being positivist or instrumentally rational in espousing that solutions to policy problems can be found if enough of the right kind of evidence can be located, or created (Hodgkinson, 2000). Clarence (2002: 4) suggested that through the 'what works' mantra, New Labour ignored decades of theory from the sociology of science, highlighting scientific controversy and that research is rarely, if ever, definitive.

For these reasons and others, research has never monopolized the policy process to the extent that policies are formulated solely, or even primarily upon evidence. Thus, a new 'realism' (Head, 2010) or pragmatism (Pearson, 2010) has emerged which has seen a dilution of the early hopes of improvements in policies and programmes resulting from closer integration between research and policy. With this in mind, alternative maxims have been adopted to explain the evidence and policy relationship, including 'evidence-informed' policy (Chalmers, 2005) and 'evidence-inspired' policy (Duncan, 2005). There has been a movement away from 'what works' to considering how evidence may or may not impact on the decision-making process (Nutley, et al, 2007). Learning from other contexts, or 'policy transfer' is one way of harnessing particular kinds of evidence.

\section{From policy transfer to policy as translation}

'Policy transfer' encompasses a range of concepts, including 'lesson-drawing' (Rose, 1993), 'policy learning,' 'policy convergence' and 'policy diffusion' (Stone, 2012) to describe how ideas, evidence and knowledge are transferred from one jurisdiction to another. Dolowitz (2009) suggests that the majority of policy learning is 'touristic' or 'soft,' policymakers simply seeing something they like and attempting to introduce it into their home context. As with the 'what works' paradigm, policy transfer tends to view the policy process as rational, linear and instrumental, but pays insufficient attention to how policies are transferred. Policy transfer studies have mostly centred upon the viability of transfer or whether 'successful' transfer has occurred, but largely failed to consider the processes involved (Dolowitz and Marsh, 2000: 7). More recent studies have begun to explore the impediments to transfer, such as the institutional and cultural contexts to offer a deeper understanding of the transfer process (see for example Dolowitz et al, 2012).

'Policy as translation' (Lendvai and Stubbs, 2007) offers an important critique of policy transfer. Rooted in the 'sociology of translation' literature and the 'interpretive turn' in social policy (Shore and Wright, 2011), 'policy translation' considers policymaking to be a 'meaning-making and claim-making process' (Lendvai and Bainton, 2012). A translation perspective sees the policy process as fluid, dynamic and continually re-constituting, rather than a linear or rational transfer process. Freeman argues that "translation might be the key to 
transfer” (2009: 430), but as Yanow (2004: 15) suggests, 'translation' is not the same as 'transfer'. Translation does not need to be entirely faithful to the original and involves a process of replication, imitation and differentiation (Barry, 2013: 3). The 'travel of ideas' necessitates dis-embedding from one institutional setting to another, bringing into play legitimation and enactment within local settings (Kirkpatrick et al, 2013: S49).

Central to both the EBPM and policy transfer/translation literatures is a concern with how ideas, evidence and knowledge are integrated into the policymaking process. At the core of both is dissatisfaction with previous policies and a normative commitment to improving the decision-making apparatus. However, both EBPM and policy translation are beset with difficulties and their success is contingent on a concatenation of processes, individuals and events facilitating policy development. The key limitation of existing EBPM and policy transfer literatures is their capacity to explain how evidence is used. Similarly, policymaker documents such as the Cabinet Office Framework for International Policy Comparisons (2008) and the Magenta Book (HM Treasury, 2011) - which sets out detailed guidance for undertaking government evaluations - do not consider how policymakers can incorporate evidence (whether domestic or international) into policy. Drawing on Newman's (2006) suggestion that policy translation risks being 'stretched' far beyond its useful meaning, we were concerned that the concept could be nebulous and difficult to operationalize in the 'real world' policymaking context. We sought to test this by presenting a series of models depicting evidence utilisation to government officials.

\section{Methodology}

Three focus groups were facilitated by the authors with 75 DWP officials in different locations around the UK between May and July 2012. Participants included policy officials and analysts (social researchers, statisticians and economists), ranging from middle-ranking officials to senior civil servants and from relatively new entrants to officials of long service. Participation in the workshops was voluntary and involved self-selection. The assumption was that participants all had some interest from their everyday roles in policy development or analysis in how evidence and policy interconnect. For reasons dictated by the coordination requirements of DWP, the methods of delivery differed in that the first focus group comprised 10 participants, the second around 25 participants and the final one around 40 participants. The focus groups ranged in length between one and two hours and participation was voluntary. The broad design was produced in consultation with the DWP; this process was itself an exercise in translation, the academic literature and concepts being translated into policymaker-relevant knowledge. Despite internal variants, there were constants in the subject matter discussed. The aim was two-fold: (i) to stimulate discussion about the translation of evidence, ideas and knowledge into policy; and (ii) to test the usefulness to policymakers of models depicting this process. The key question posed was: 'How is evidence used, or translated?' Conceptual models based on the EBPM and policy transfer/translation literatures were presented to officials as a basis for discussion.

The DWP constituted a fertile testing ground for exploring the evidence and policy interface. Legrand (2012: 330) suggests that the growth in its research outputs between 2004 and 2010 demonstrated an "extraordinary sea change in their use of research evidence in policy development and evaluation". The study built on links established during previous doctoral research co-funded by the DWP (Ingold, 2011). At the time of the study the organisation was engaged with a wider agenda of cross-government approaches, including 'horizon scanning': 
looking across a spectrum of evidence to shape policy developments. Officials were engaged in developing the Coalition Government's flagship Universal Credit, involving a "radical restructuring of the benefits and Tax Credits system" (DWP, 2011), including the introduction of 'in-work conditionality' and operational flexibilities in Jobcentre Plus. For these reasons the project constitutes a rare case study account of a government department during a time of significant organisational and policy change.

\section{The models}

The first model presented to officials was a linear depiction of both EBPM and policy transfer (Figure 1). The linear model portrays a direct link between evidence production and policymaking and can be considered an amalgamation of the 'knowledge-driven model' and the 'problem-solving model' of research utilisation (Weiss, 1986). The former suggests that existing data can be harnessed and applied to a policy problem in the hope of garnering a solution. The latter is similar; it is at the point where evidence is obtained that departure occurs. In the problem-solving model evidence is specifically commissioned, with the research being 'on tap,' while in the knowledge-driven version the research is 'on top' (Young et al, 2002).

The linearity of policy transfer can be critiqued on similar grounds as the limitations of EBPM models. Policy transfer studies have tended to focus on the 'degree of transfer' (Dolowitz and Marsh, 2000). Beginning with the impetus for transfer, whether voluntary or coercive, Dolowitz's (1996) policy transfer framework considers 'who' is involved in transfer and 'what' is transferred (whether policies, programmes, institutional structures, ideologies, or ideas). However, the constraints on transfer have hitherto received less attention in policy transfer studies; these contextual and interpretive elements are key to policy translation.

\section{Figure 1 here}

The second model presented for discussion was the 'Processual Model' (Figure 2), which is a synthesis of models of research utilisation and EBPM. In this model 'evidence use' occurs in the process of policy formulation and analysis. In this way it is akin to Weiss' (1986) 'enlightenment' model of research utilisation, whereby research supplies the conceptual tools to policymakers to aid their decision-making but rarely, if ever, directly shapes it. Although the enlightenment model offers a promising opportunity for evidence to influence policy, the 'indirect diffusion' of evidence that typifies the enlightenment model can lead to 'distortion' and 'over-simplification' and there is little consideration that other factors can drive policymaking. A major drawback of the enlightenment model is that it is based on the assumption that all kinds of research, regardless of theoretical standpoint and methodological preference, have an equal chance of influencing the policy agenda (Stevens, 2007). As the history of EBPM reveals, the ability to shape or affect the agenda is not an equal playing field (Stevens, 2007; Monaghan, 2011). With this in mind, Stevens (2007) has developed an evolutionary model of the evidence and policy relationship, which drew closely on what Weiss terms the 'political' and 'tactical' models. For Stevens evidence selection depends on it surviving a number of filtration mechanisms in the decision-making process:

- fishing - where policymakers 'fish' or 'trawl' for evidence, haul in the bits they require and throw back those not required; 
- farming - where powerful groups 'farm' or cherry-pick evidence, commissioning research to provide evidence for a proposed policy, but only publishing that which supports the policy;

- flak - where disquiet is directed towards producers of evidence detrimental to a chosen policy direction, the overall aim being to discredit troublesome evidence relating to a controversial policy;

- 'strain' - constraints are placed on organisations or individuals who produce and advocate 'unhelpful' evidence.

\section{Figure 2 here}

Stevens (2007:29) concludes that for evidence to be used in policy it has to survive attempts to filter it out, a process which is achieved by finding powerful sponsors who advocate particular kinds of evidence in policy. As Figure 2 shows, the Processual Model shares the evolutionary model's view that evidence which survives the various filtration mechanisms stands the best chance of being used in policy, but takes its point of departure at the moment of decision-making. The evolutionary model seems to suggest that evidence that survives will be used but this downplays the role of agency in the policy-making apparatus and the inherently unpredictable nature of policy - political and economic imperatives often sway decisions one way or another, even if the evidence suggests otherwise. The Processual Model accepts that evidence is embedded in the policy process and could percolate into decisionmaking, but this is by no means a foregone conclusion, nor is the connection straightforward hence the double-ended arrows at the bottom of the diagram. At the centre of decisionmaking is semi-autonomous agents who engage in 'meaning making' - here the model overlaps with policy translation.

For the first time 'policy translation' has been depicted in diagrammatic form (Figure 3). The model incorporates 'stages' of policy translation but is intended to be recursive, with no specific beginning or end. For the purposes of describing the model, one possible starting point is the construction of a policy 'problem' (top-left). Looking for learning from other contexts depends on how policy problems are initially constructed and framed. The impetus for policy learning can stem from dissatisfaction with or the perceived failure of current policy. Bacchi (1999; 2009) suggests that policies are not 'out there' waiting to be discovered and solved by the policy community, but are constructed; the construction (and reconstruction) of a policy problem may be returned to at any stage of the process.

The upper-right quadrant of the model considers where to look for ideas, evidence or knowledge. The unit of analysis need not be constrained to the national level. Both academics and policymakers tend to assume that 'successful' policy transfer may be achieved by looking for policy learning from similar contexts, obscuring the search for policy learning from countries which are perceived as being too 'different' (Lendvai and Bainton, 2012). Policy translation emphasises that "Policy is not available to be looked at and learned from but is produced in the act of looking" (Lendvai and Stubbs, 2007: 180) and the countries (or contexts) which policymakers (and researchers) choose involves bias and filtration.

\section{Figure 3 here}


The bottom-right quadrant considers the constraints on how evidence, ideas and knowledge are used. This involves interpretation, or what Kirkpatrick et al (2013: S49) refer to as 'enactment' and 'embedding' by institutional actors. Interpretation is the most important component of the knowledge utilisation process but the most difficult to observe (Ettelt et al, 2012: 494). It is explicitly political, binding together and forming systems and governance which bring power back in, drawing attention to 'what gets translated and by whom' (Lendvai and Bainton, 2012, Needham, 2011). Policy translation thus makes agency central and for this reason 'translators' are at the epicentre of the model: people, organisations and networks are fundamental to and drive the policy process (Bissell et al, 2011). Importantly, the model views actors as embedded within the contexts in which they operate, not independent of it (Dolowitz et al, 2012).

Finally, the bottom-left quadrant considers the 'tiers' of policy translation: the levels of policy design and implementation. Implementation is a process of interaction, evolution, mutual adaptation and exploration (Pressman and Wildavsky, 1984; Freeman, 2009) which is recursive, with continuous re-interpretation of the evidence throughout the policy process. In the act of translation, evidence from other contexts goes through an iterative process of deterritorialisation, re-territorialisation, reconstitution and re-siting (Ingold, 2011).

\section{Findings}

Before undertaking the research, the authors' hypothesis was that the Processual and Policy Translation models were compatible and this was tested by encouraging officials to consider the utility of the models to their experience of the incorporation of evidence from both the UK and overseas. The following sub-sections discuss the findings from the study in relation to key themes in the models.

\section{i. Policy problems}

There was a consensus amongst officials at all three focus groups that the Processual and Policy Translation models, rather than the Linear model, more accurately represented the 'messy' and complex reality of policymaking.

"This is the kind of thing we need, more than a kind of linear one. In reality I recognize large chunks of that and I'm sure others here do too but this is different with every policy. There is lots more to add - e.g. the political timeframe we are working to. For example a 10 year policy cycle, alongside a 5 year election cycle.”

Both this and the following quote highlighted a recurring theme: that of 'time'. As DussaugeLaguna (2012) has suggested, the temporal dimension has been neglected by existing policy transfer studies. In particular, the concept of 'Zeitgeist' was considered to be important, both in relation to the process as a whole and specifically to the framing of the policy problem:

"Both models seem time static. The Zeitgeist seems to be taken as a given, it is not fluid.”

We will return to this point, but it was apparent that the contemporary political and policy culture was a defining factor on the appreciation of evidence at a particular point in time. In other words, there was some discussion amongst officials regarding where 'external factors' such as 'the economic and political' featured in the models. Perhaps unsurprisingly officials 
viewed the economic (austerity) context as an important factor in the framing of the policy problem. However, the general context of resource constraints was considered to frame not only the search for evidence, but also the differential representations of the policy problem (Bacchi, 2009):

"In the working age benefits policy area the main thing recently is that it's very much to do with cost rather than looking at the evidence in the first place to see what the policy should be."

"It goes back to the different layers of people's policy outcomes and their agendas. It's almost layered in terms of different people's viewpoints...looking at the full problem is too expensive so let's sort this bit out first and deal with that bit later, or we can't afford that bit at all so let's not bother looking at it.”

During another focus group this issue was raised again, this time in relation to policy learning from Denmark:

“...do we not learn from Denmark because their policies are perceived as being too expensive, it's a bit about the evidence hierarchy. But one of the problems we have in DWP is that we tend to only look at the costs of implementing the policy and not the overall cost to the social security system so AME as opposed to DEL. And so it might be a really expensive policy but in the long-term it's going to save you more AME than DEL. Even in austerity times we should be doing it because it costs less to the government overall.”

DEL refers to government departmental ('designated expenditure limits') which are fixed budgets; AME ('annually managed expenditure') is expenditure which cannot be planned for. The latter includes the social security budget, on which an absolute limit had not historically been placed until the Coalition Government's 2013 Spending Round introduced a 'welfare spending' cap. Following on from New Labour, the Coalition has looked towards 'invest-tosave' models, in which benefits expenditure can be saved by investing in employment programmes (such as the Work Programme). In this context, another official highlighted that a policy from another domain could appear effective in terms of outcomes, but resources might preclude translation:

“From my perspective you've got the general resource constraints, you've got plenty of austerity measures and you will get to the stage whereby, yes, this is fantastic but plainly and simply we haven't got the resource either people-wise or financial to be able to do it...Therefore it gets quashed."

Moving down a level of abstraction, the notion that evidence use is contingent on the specific policy instruments deployed was commented upon. In our research this very much focused on who stood to 'gain' and 'lose' from a particular policy and how this was expected to play out with the public and media:

“...values are important as well as ideology. There are different impacts of policy and it's how those impacts are weighted." 
This perspective intersects with the growing literature on ideational policy change (Béland and Cox, 2011, p.3), in which narratives and 'stories' are constructed by policy actors, contributing to a weight of evidence in a particular direction, building coalitions as well as side-lining critics (Needham, 2011). This includes the displacement of dissenting voices (Lendvai and Stubbs, 2007: 177), which can in turn shape where policymakers look for evidence and what they look for.

\section{ii. Ideas, evidence and knowledge}

The notion of 'fishing' and 'farming' for evidence in both the Processual (and therefore the evolutionary model) and Policy Translation models struck a chord with officials:

"I think the processual model has similarities with how we operate now, certainly the fishing and farming aspects."

This led to discussion about the purpose of evidence. Officials considered that the recursiveness of the Policy Translation model allowed for different scenarios, such as whether evidence contributes to policy development, or whether it is used to justify policies which have already been decided: what is termed 'policy-based evidence' (see for example Sharman and Holmes, 2010). The following quotes underline the role of agency within this process:

"What often happens but not in all cases is that policies are piloted, but not in the sense of 'Let's run it for three years, do the evaluation and decide where to take it'. You run it for three years and after the first 6 months you have your data and that will be the evidence that will be used to design the rollout, perhaps to give the 'sheen' of evidence-based policy.”

"What's the desired outcome from actually doing that might change under different agendas, different political views. And it goes back to that translation, that you can collect some evidence that under that policy outcome will drive you down that direction but if the policy outcome is slightly different then actually the translation of that needs to be looked at in a slightly different context."

However, there was also a recognition that evidence may not progress to the filtration process or translation cycle in the first place:

"A lot of the evidence doesn't even get that far. It is out there but the policy makers don't know about it. It is not always clear what the evidence base is and that is a real sticking point."

This contradicted a point made in another focus group about the evidence base being easy to harness:

"I think in the academic literature there's generally a consensus and you can work that out pretty quickly”.

These differing viewpoints may suggest evidence gaps for particular policy domains, as well as reflect the varying experiences of officials in different parts of the organisation. The 
localised dimension of service delivery through Jobcentre Plus meant that what constituted evidence was differently perceived:

"I think experience is important as well. I did a lot of work on lone parent programmes and you talk to the field and they said 'We did that about 5 years ago' and these are the lessons learned. So things come around again in different packages. Maybe at operational level there's this accumulated knowledge, if you have advisers that have been there for quite a while they will be aware of what's gone before, so they may not have any formal evidence like our reports, but they will certainly be using experience.”

Officials considered it important that a useable model should be able to accommodate the utilisation of one piece of evidence, as well as a 'weight' of evidence:

"It seems as if you are talking about a single bit of evidence and how that might impact on policy, but when there is a large body of evidence that might influence the Zeitgeist or alter the agenda.”

These findings highlight the 'patchwork' of information which can be perceived as evidence (Pawson, 2006;) and the following section explores how such evidence is 'filtered' in the translation process.

\section{iii. Interpretation}

A number of aspects were discussed in relation to interpretation and can be summarised by the following quote:

"I think it's a triangle - so you've got what you want to do politically, what the evidence says and what is operationally feasible and you're trying to find a space in the middle."

This appears to support Rose's assertion (1991: 24) that policy transfer should be judged against two key standards: technical feasibility and political feasibility. In particular, officials considered that occupational roles and professional identities could impact on the way that evidence is used:

"Just in terms of the Processual Model, in terms of things getting ingrained in people's minds and in policymakers' minds, I definitely know that where I've worked in divisions where all the policymakers had a really, really old collective memory of evidence and it is ingrained and you do wonder if that changed how long would it take to change? It's really great on the one hand because you don't have to have these conversations all the time about 'Do you realise this and do you realise that' but it's interesting in terms of how long does it take to then change something."

This quote reflects a number of comments made that suggested that institutional memory is not necessarily lost in modern bureaucratic organisations (cf Pollitt, 2000), however it relies on well-placed individuals to account for it at key stages in the policy process. The following two comments illuminate how an actor's location within the organisation (Simon, 1997: 325) can act as a filtration mechanism for how evidence is translated: 
"For us it's butting in when you see the opportunity. Maybe this is organisational because it depends on the structure of the division...I'm in a purely analytical division at the moment but I used to be based in a division that had both analysts and policy colleagues and very close working relationships with operations. And so it was natural day-to-day conversations in which you'd be talking about things. Whereas now I have to make the effort to keep chipping away and saying 'If you look at the evidence, it doesn't necessarily work well in that way'.”

"Ours is more a political/analytical division so the evidence is maybe closer to me in terms of how it works in reality. So there does seem to be more of an ongoing conversation around influencing things.”

An unexpected and at first-glance somewhat paradoxical finding, bearing in mind the emphasis on experiential knowledge highlighted in the preceding sections was that methods served as a filtration process: officials considered methodology to be important in influencing where decision-makers look for evidence and the evidence they are likely to trust. This contrasted with Ettelt et al's finding that officials in the Department of Health officials (2012: 498) were unconcerned about the quality of information:

"From a research point of view there is a reluctance to go for anything other than numbers. Qualitative data value added is pushed to the back a bit. It is becoming more prevalent now but there still seems to be a priority on quantitative data. Generally because people do not understand the value of qualitative research especially around the issue of sample sizes. They do understand percentages for example, they get that concept but there is some misunderstanding of the value of qualitative.”

A methodologically-based evidence hierarchy, however, was not key to evidence utilisation; rather, officials were concerned about how particular methodologies would be perceived by key decision-makers, suggesting that it is evidence which maps onto dominant ideology, electioneering and 'playing to the gallery' which is most effectively translated into policy. Similarly, the following comment was made in relation to the influence of the British Social Attitudes Survey (BSAS) and the media on policy development:

"When we were doing stuff for lone parents Ministers were very interested in the BSAS evidence but that's stuff that we don't have any control over. It's evidence that's coming in from the public arena and if you think about the changes to welfare payments, the benefit cap and the reaction of the majority press was very positive towards putting more stringent conditions on welfare receipt...There are other things that we just can't control and it's how you factor those in."

Our findings challenge the idea that all kinds of research, regardless of theoretical standpoint and methodological preference, have an equal chance of influencing the policy agenda (Stevens, 2007). This is in line with a sociology as translation perspective and the idea that method is 'interactively performative', enacting different realities and producing different and inconsistent results (Law and Urry, 2004: 396-7). 


\section{iv. Policy apparatus}

The legislative apparatus is central to this quadrant, appearing to have a significant bearing on whether evidence is used or translated:

"There are precedents, some of them are legal, there are only so many things we can do within the legislation but others are quasi-legal, or quasiorganisational, how you've always done it. It does sometimes feel that you can't introduce something that's too radical because even elements of Universal Credit are built on the legislation and the regs [sic] that sit around benefit claiming.”

"Because although if we suddenly came up with something tomorrow which showed, I don't know, that's there no point in people having personal adviser meetings, that something that's been so ingrained for so long it kind of needs a huge weight of evidence behind it to shift people's perceptions.”

This underscores the incremental nature of policy change depicted by Streeck and Thelen (2005) and in particular their concept of 'layering' as a mechanism through which institutional change occurs despite path dependency and vested interests. As Beckert (2010) suggests, institutional homogeneity or isomorphism is not a foregone conclusion, either within or between countries. Central to policy translation is the acknowledgement of uncertainty and the recognition of complexity (Freeman, 2009: 440; cf Sanderson 2002, 2009). Building on this, officials suggested that the policy translation model could be further developed to depict how interpretation can occur in different scenarios:

“...you might think, why is my evidence not being used effectively in this policy making environment then that model might help you understand what is underpinning why people aren't taking it seriously... if the policy is already decided then that is a different matter to people actually not understanding the evidence that you are putting forward, or the way you are explaining doesn’t make sense. Or, if you haven't fully understood the context in which that person is receiving that information. I think it might help in those kind of ways, but it doesn't show how people filter and interpret the information that is brought to the policy making process."

Underlining the recursiveness of the policy translation model, the economic dimension was again considered to be important at this stage of the process:

"Quite often you can come up with a solution but when it starts filtering down and starts going through the legislative process, Treasury start chipping away at it and financial constraints come in and at the very end process the policy is still changing. That links to the external constraints."

This points to the political elements once again and mirrors Tonry's (2004) assertion that political expediency frequently trumps evidence when political stakes are high. These elements emphasise the centrality as well as fluidity of the interpretation and re-interpretation of ideas, evidence and knowledge; key to this process are translators. 


\section{v. Evidence to policy translators}

The agency of those within the policy process is central to how evidence is acquired, how it is or is not used and to how policy is developed. This is illustrated by the following comment about the changing nature of service delivery through Jobcentre Plus local flexibilities, as well as joint-working with HMRC to deliver Universal Credit:

"What I like about this is that you've got people and organisations at the centre because you look at some of the policies and we must think about different ways of delivering our services...in terms of change between the central and the local and discretion at local level creates massive challenges from an evidence point of view...currently there is actually a lot of influence the field can have in terms of how the evidence if translated."

"Locally you have a degree of autonomy and they do their own gathering of what they think is evidence...this is part of the patchwork quilt of evidence...And this kind of evidence quite often carries a lot of weight if someone keen in a local area does something interesting, we might 'tut tut' quietly but it doesn't matter because for the senior manager it's interesting and they run with it and roll it out regardless of how actually robust it is."

Another official emphasised that it was important to identify the range of influential actors, which could vary at different stages of the process:

"We need to think about who are the key people, the key actors at each stage of the process. All have agendas and are influenced by and influence others, policies, mood, ideology. They are not just a Minister.”

Similarly, the following comment highlights the role of officials in translating evidence, within the constraints of the local context, including their professional role:

“...being cynical you could say, 'How much is actually ignored or you could say 'quality-adjusted' to say it's not quite what we wanted, but...this is the one that I'm going to drive forward and put my professional backing behind."

This underscores the importance of 'enactment' within policy translation (Law and Urry, 2004: 392). Translation is a form of power (Barry, 2013: 2). However, local history, traditions and institutions form an important backdrop to how actors in a given setting engage with ideas (Kirkpatrick et al, 2013). For example, officials noted that their influence could be limited and considered Universal Credit to be driven by ideology, which not only framed the search for evidence but also constrained its use:

“...obviously they came in with this massive vision about what Universal Credit was going to be, they had it on the Work Programme as well. There's less room sometimes to influence the debates with the evidence, because some of the big ideas are already quite set.”

As with the policy problem quadrant, time was again viewed as important and officials considered that further development of the models was required to reflect this dimension. 


\section{The Evidence Translation Model}

Following the final focus group a modified version of the 'Policy Translation' model was developed, integrating the Processual Model (Figure 4). To reflect this, it has been labelled the 'Evidence Translation' model. The key modifications are as follows.

- Zeitgeist seemed to more accurately describe the context of the construction of the policy problem, as well as the temporal dimension, which was considered important to the entire process.

- 'Agenda-setting' is a key component of evidence utilisation, influencing where officials look for learning and the precise kinds of evidence that are likely to be used.

- In the bottom-right quadrant the filtration process from the Processual Model has been incorporated to illustrate how ideas, evidence and knowledge are utilised in policymaking. This filtration includes what we refer to as 'organisational resistance' in terms of the organisational structure and the location of actors.

- The bottom left-hand quadrant has been re-named 'policy apparatus' to refer to the policy instruments and settings, such as legislation that play a key role in evidence utilisation in different scenarios.

- The central position of translators in the model remains the same. The capacity of agents to influence the evidence translation process is depicted by double-ended arrows. This is consistent with how the Processual Model departs from the evolutionary model of research utilisation, demonstrating the agency of actors within the policymaking process, but that this agency is constrained at different stages and in different permutations of the evidence translation process.

\section{Figure 4 here}

The Evidence Translation Model is presented for further discussion and critique, with the knowledge that more development is required, as illustrated by the following comment from an official:
"It is useful to have these 'how these things happen' models but how do we improve on that? So I think these are reasonable descriptions of how evidence is used but I think everyone in the room would agree that it is not always done correctly so you are describing a system that has problems in it. The use of these potentially is in trying to highlight where the problems are and how to fix them.”

\section{Conclusion}

This paper has aimed to further the debate regarding whether and how evidence from home or overseas contexts is utilised in policymaking. By combining the evidence-based policymaking and policy transfer and policy as translation literatures, the paper contests that central to each is a concern with how evidence, ideas and knowledge are integrated into the 
policymaking process. The paper has critiqued and fused existing models of evidence utilisation and policy transfer and for the first time depicted 'policy translation' in diagrammatic form. Before undertaking the research, it was hypothesised that the 'Processual' and 'Policy Translation' models developed by the authors were compatible. This was tested by undertaking focus groups with Department for Work and Pensions officials to explore the utility of the models to their experience of incorporating evidence - both UK and international - into policy. Following this testing, a revised and actor-centred model of ‘Evidence Translation’ was developed, incorporating five key dimensions:

(i) the substantive nature of the policy problem in the context of the Zeitgeist

(ii) 'agenda-setting' -where evidence is sought (fishing/farming) and what evidence is used

(iii) The filtration processes which shape and mould how evidence is used (flak/strain) - including the perceived influence attributed to different methodologies, experiential knowledge and the role of organisational resistance arising from the organisational structure and the location of evidence translators

(iv) the policy apparatus for policy design and implementation - this includes legislation and involves a continual process of interpretation and re-interpretation

(v) the critical role of evidence translators at every stage of this recursive process, within different scenarios which form the context and purpose for evidence selection and use

The Evidence Translation model is not intended to 'essentialise' the complex policy process into an order that cannot be realistically achieved (Stone, 2012: 497). Nor is this desired. The Model is intended to contribute to an on-going debate about the mechanisms impacting upon the utilisation of evidence, ideas and knowledge in policymaking. How this process can be better facilitated requires further exploration and testing both within (and across) academic and policy communities. This should include consideration of the critical role of 'evidence translators', the influence of different methodologies and the temporal dimension. One possibility is the development of an 'Evidence Translation Toolkit' for policymakers. This paper constitutes a rare case study account of actors in a government department during a time of significant organisational and policy change. However, the increasing involvement of private and non-profit organisations in the delivery of employment services and the accompanying 'privatisation' of data underscores the importance of involving a wider range of actors in considering the process of evidence translation. The recent reports of Coalition ministers' 'misuse' of statistics (for example, The Economist, 2013) suggests that the debate regarding the key factors which drive evidence utilisation are as important as ever.

\section{Acknowledgements}

The project on which this paper is based was funded by the Higher Education Innovation Fund. The authors wish to thank the Department for Work and Pensions, Laura Davies, Joanne Greenhalgh and David Etherington for their assistance with this project and the 2 anonymous reviewers for their helpful comments on earlier drafts of the paper.-

\section{References}


Bacchi, C. L. (2009) Analysing policy: what's the problem represented to be? Frenchs Forest, NSW: Pearson

Bacchi, C. L. (1999) Women, Policy and Politics: the Construction of Policy Problems, London: Sage.

Barry, A. (2013) 'The translation zone: between actor-network theory and international relations', Millennium: Journal of International Studies, 41(3): 413: 429.

Beckert, J. (2010) 'Institutional isomorphism revisited: convergence and divergence in institutional change', Sociological Theory, 28(2): 150-166.

Béland D., Cox R. H. (eds) (2011) Ideas and Politics in Social Science Research, Oxford: Oxford University Press.

Bissell, K., Lee, K., Freeman, R. (2011) 'Analysing policy transfer: perspectives for operational research' The international journal of tuberculosis and lung disease, 15(9):11408.

Cabinet Office (2013) What Works: Evidence Centres for Social Policy, London: Cabinet Office.

Cabinet Office (2008) Beyond the Horizon: International Comparisons in Policymaking, London: Centre for Management and Policy Studies.

Chalmers, I. (2005) 'If evidence-informed policy works in practice, does it matter if it doesn't work in theory?’ Evidence and Policy 1(2): 227-42.

Clarence, E. (2002) 'Technocracy reinvented: The new evidence-based policy movement' Public Policy and Administration 17(3): 1-11.

Daussage-Laguna, M. (2012) 'The neglected dimension: bringing time back into crossnational policy transfer studies’ Policy Studies 33(6): 567-585.

Department for Work and Pensions (2011) Universal Credit: Welfare That Works (Cm 7957), London: The Stationery Office.

Dolowitz, D. (1998) Learning from America: Policy Transfer and the Development of the British Workfare State, Brighton: Sussex Academic Press

Dolowitz, D. P. (2009) Learning by observing: surveying the international arena, Policy \& Politics, 37(3):317-34.

Dolowitz, D. \& Marsh, D. (2000) 'Learning from abroad: the role of policy transferin contemporary policy-making’ Governance, 13(1), 5-23. 
Dolowitz, D., Keeley, M., Medearis, D. (2012) 'Stormwater management: can we learn from others?’ Policy Studies 33(6): 501-521.

Downe, J., Martin, S., Bovaird, T. (2012) 'Learning from complex policy evaluations’ Policy \& Politics 40(4): 505-23.

Duncan, S. (2005) ‘Towards evidence-inspired policy-making’ Social Sciences, (61): 10-11.

Ettelt, S., Mays, N. and Nolte, E. (2012) 'Policy learning from abroad: why it is more difficult than it seems’ Policy \& Politics 40(4): 491-504

Freeman, R. (2009) 'What is translation?’ Evidence and Policy 5(4): 429-47

Gains, F. and Stoker, G. (2011) 'Special advisors and the transmission of ideas from the policy primeval soup’, Policy \& Politics, 39 (4) 485-498

Head, B.W. (2010) 'Reconsidering evidence-based policy: key issues and challenges' Policy and Society, 29 (2): 77-94.

HM Treasury (2011) Magenta Book. Available at:

http://www.hmtreasury.gov.uk/data_magentabook_index.htm

Hodgkinson, P. (2000) 'Who wants to be a social engineer? A commentary on David Blunkett's Speech to the ESRC', Sociological Research Online 5(1).

Ingold, J. (2011) An international comparison of approaches to assisting partnered women into work. DWP Working Paper No. 101. Sheffield: Department for Work and Pensions

Kirkpatrick, I. , Bullinger, B. Lega, F. and Dent, M. (2013) 'The translation of hospital management models in European Health Systems: a framework for comparison', British Journal of Management, 24: S48-S61:

Lapaige, V. (2010) “"Integrated knowledge translation” for globally oriented public health practitioners and scientists: Framing together a sustainable trans-frontier knowledge translation vision', Journal of Multidisciplinary Healthcare, 3 33-47.

Law, J. and Urry, J. (2004) 'Enacting the social’, Economy and Society, 33(3): 390-410.

Legrand, T. (2012) 'Overseas and over here: policy transfer and evidence-based policymaking’, Policy Studies, 33(4) 329-348

Lendvai, N. and Stubbs, P. (2007) Policies as translation: situating transnational social policies, in Hodgson, S. M. and Irving, Z. (Eds.) Policy Reconsidered: Meanings, Politics and Practices. 
Lendvai, N. and Bainton, D. (forthcoming, 2012) 'Translation: Towards a critical comparative social policy agenda' in Kennett, P. Handbook of comparative social policy (second edition), Cheltenham: Edward Elgar.

Monaghan, M. (2011) Evidence Versus Politics: Exploiting Research in UK Drug Policy Making, Bristol: Policy Press

Needham, C. (2011) 'From policy transfer to policy translation: the role of evidence in policy borrowing', in Glasby, J. (ed) Evidence, Policy and Practice: Critical Perspectives in Health and Social Care, Bristol: Policy Press.

Newman, J. (2011) 'Boundary troubles: working the academic-policy interface, Policy \& Politics, 39 (4) 473-484.

Nutley, S. M., Walter, I. and Davies, H. T. O. (2007) Using Evidence: How Research Can Inform Public Services, Bristol: Policy Press.

Nutley, S.M., Downe, J., Martin, S. and Grace, C. (2012) Policy transfer and convergence in the UK: the case of local government performance improvement regimes, Policy \& Politics, 40 (2) 193-209

Parsons, W. (1995) Public Policy, Cheltenham: Edward Elgar.

Pawson, R. (2006) 'Digging for nuggets: how 'bad' research can yield 'good' evidence, International Journal of Social Research Methodology, 9 (2) 127-42.

Pawson, R. (2013) The Science of Evaluation: A Realist Manifesto, London: Sage

Pearson, M. (2010) 'What do we know? What should we do? Melding research validity and rhetoric in the analysis of policy making? Evidence and Policy 6(1) 77-90.

Pollitt, C. (2000) 'Institutional amnesia: a paradox in the information age'?' Prometheus 18(1): 5-16

Pressman, J. and Wildavsky, A. (1984) Implementation (Third Edition), Berkeley: University of California Press.

Rose, R. (1991) 'What is lesson-drawing?’ Journal of Public Policy, 11(1): 3-30

Rose, R. (1993) Lesson-drawing in Public Policy: a Guide to Learning Across Time and Space, New Jersey, NY: Chatham House.

Sanderson, I. (2002) 'Evaluation, policy learning and evidence-based policy making’, Public Administration 80(1), 1-22.

Sanderson, I. (2009) 'Intelligent policy making for a complex world: pragmatism, evidence and learning’, Political studies 57(4): 699-719. 
Sharman, A. and Holmes, J. (2010) Evidence-based policy or policy-based evidence gathering? Biofuels, the EU and the 10\% target. Environmental Policy and Governance, 20(5): 309-321.

Shore, C. \& Wright, S. (2011) Conceptualising policy: Technologies of governance and the politics of viability in Shore, C., Wright, S. and Però, D. (eds) 'Policy worlds: Anthropology and the analysis of contemporary power', New York: Berghahn.

Simon, H. (1997) Administrative Behavior: A study of decision-making processes in administrative organizations. New York, NY: The Free Press.

Stevens, A. (2007) 'Survival of the ideas that fit: an evolutionary analogy for the use of evidence in policy’ Social Policy and Society 6(1): 25-35.

Stevens, A. (2011) 'Telling policy stories: an ethnographic study of the use of evidence in making policy on drugs and crime, Journal of Social Policy, 40 (2) 237-55

Stone, D. (2012) ‘Transfer and translation of policy’ Policy Studies 33(6): 483-499

Streeck, W. and Thelen, K. (2005) Beyond continuity: institutional change in advanced political economies. Oxford: Oxford University Press

The Economist (2013) The coalition's statistics: Stats, spats and spads. 8 June, 2013

Tonry, M. (2004) Punishment and Politics: Evidence and Emulation in the Making of English Crime Control Policy, Cullompton: Willan.

Weiss, C.H. (1986) 'The many meanings of research utilisation', in M. Bulmer (ed) Social Science and Social Policy, London: Allen Unwin.

Yanow, D. (2004) How does a Policy Mean? Washington DC: Georgetown University Press.

Young, K., Ashby, D., Boaz, A. and Grayson, L. (2002) 'Social science and the evidencebased policy movement’ Social Policy and Society 1(3): 215-224. 